\title{
An Activity Program for Older People
}

\author{
Akehsan Dahlan, Syamsul Anwar Sultan Ibrahim \\ Occupational Performance and Behaviour Measurement Group (OPERA-RIG), Occupational Therapy Department, \\ Faculty of Health Sciences / CORE Humanities and Quality of Life, \\ Universiti Teknologi MARA, Kampus Puncak Alam, 42300 Selangor, Malaysia \\ akehsan@puncakalam.uitm.edu.my
}

\begin{abstract}
Older people in an institution live in a sedentary lifestyle. They lose their autonomy, seldom engage in activities and did not have a meaningful social relationship. These issues lead to decreased in quality of life (QoL). The aim of this randomised trial is to determine the effectiveness of a lifestyle redesign programme, i.e. the Lively Later Life Programme (3LP) on QoL. Eighty-two older people who fit the inclusion criteria were randomly assigned to the $3 \mathrm{LP}$ group and the control group. At the end of six months, there is a significant change in physical, psychological and social domains of QoL.
\end{abstract}

Keywords: Older people; quality of life; activities; lifestyle.

eISSN: 2398-4279 @ 2017. The Authors. Published for AMER ABRA by e-International Publishing House, Ltd., UK. This is an open access article under the CC BY-NC-ND license (http://creativecommons.org/licenses/by-ncnd/4.0/). Peer-review under responsibility of AMER (Association of Malaysian Environment-Behaviour Researchers), ABRA (Association of Behavioural Researchers on Asians) and cE-Bs (Centre for EnvironmentBehaviour Studies), Faculty of Architecture, Planning \& Surveying, UniversitiTeknologi MARA, Malaysia.

https://doi.org/10.21834/ajqol.v2i6.41 


\subsection{Introduction}

There are increasing numbers of older people in Malaysia who are seeking care from private or public elderly institutions. Previous studies show that older people who live in the institution faced with various issues that lead to decreased in quality of life (QoL). There are various health programmes that have been conducted to prevent the issues, for example, programmes that redesign a lifestyle through re-engagement in individualised, meaningful, valued and self-directed activities. However, such programmes have only been conducted in developed countries and were designed for older people who live in community settings (Mountain et al. 2008; Frandin, et.al, 2013). There is no substantial work exploring the applicability and the effectiveness of such programmes for institutionalised older people in Malaysia. Hence, the aim of this study is to evaluate the effect of a programme that modifies older people lifestyle in institutions through a lifestyle redesign programme known as The Lively Later Life Programme (3LP).

\subsection{Literature Review}

Older people in the institution live in a sedentary lifestyle and seldom engage in activities (Haslam, 2008; Dahlan \& Ibrahim, 2014). They spend a high proportion of their daily life being inactive, alone or immobile (Ice, 2002), spend many hours in bed and frequently taking a nap during the day (Neikrug \& Ancoli-Israel, 2010). Ice (2002) investigated the daily life of older people in a nursing home found that the resident spends $56 \%$ of their time doing nothing. The majority of them spent their time in their room, sitting alone, not doing anything and contemplating the past. Chung (2004) found institutionalised older people spent $90 \%$ of their time engaged in passive activities. The older people stated that '... every day is the same' (Chuang and Abbey 2009: p.1644), and they felt '[the] time stands still' (Cook and Stanley (2009: p. 397)

Furthermore, the relationship between residents in institutions is seldom a meaningful type of relationship. It is often for adjustment (Chuang \& Abbey, 2009) a compromised relationship to ensure harmony (Lee, 2010), in-frequent, non-intimate and a fragile type of relationship (Spilsbury, et al., 2011). The relationships with staff are often formal in the manner (Spilsbury, et al., 2011) which subsequently leaves the resident alone and doing nothing. Visits from family members and friends often decline over time (Fukahori, et al., 2007; Cheng et al. 2010). They also experiencing institutionalised syndrome as a result of erosion in personal autonomy, lack of internal locus of control, loss of personal space, loss of meaning and sense of belonging in life (Choi, et al., 2008; Custers, et.al., 2012). Subsequently, there are many older residents who feel powerless, depressed, low selfefficacy, low self-esteem and decreased general well-being (Choi, et al., 2008; Boyce, et al., 2012), which subsequently affected their QoL (Hedberg, et al., 2010). 


\subsection{Methodology}

The study conducted in a public funded elderly institution in Malaysia that houses elderly people, 60 years old and above. A Pre-test-Post-test parallel experimental study design with a control group was chosen to investigate the effect of 3LP on QoL. To be included in this study, the participants had to meet the following criteria (I) aged 60 years or older; (II) independent in basic self-care skills; (III) able to speak in either in Bahasa or English, (IV) have scores of 22 or above in Malay Mini-Mental State Examination (MMSE); (V) have scores below seven in the translated version Geriatric Depression Scale (GDS). A compromise power analysis based on the $\mathrm{G}^{*}$ Power calculation analysis was conducted to determine the sample size. All of the participants were randomly allocated using random allocation software (Saghaei, 2004). The post-test conducted by independent researchers who were blinded to the aim, theoretical framework, participation allocation and the nature of the 3LP.

Data regarding QoL was collected using Malay version of the brief version of World Health Organisation Quality of Life (WHOQOL-Bref) (The WHOQOL Group, 1995; Hasanah et al., 2003). It covers four main domains and contains 24 facets of QoL, i.e. physical health (7 facets), psychological (6 facets), social relationship (3 facets) and environment (8 facets) (The WHOQOL group, 1995). The study was approved by the Research Ethics Committee of Universiti Teknologi MARA and the Department of Social Welfare in Malaysia. Informed consent was obtained and collected from all of the participants.

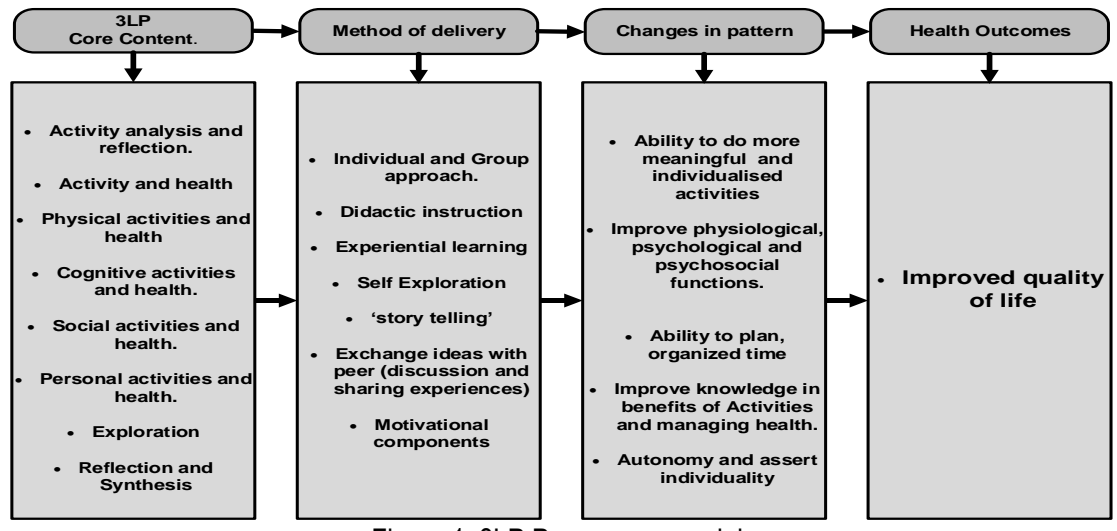

Figure 1: 3LP Programme model.

Participants in the control group received programme conducted by the staff of the institution. The programme is an ad-hoc programme, comprising mainly of recreational and social types of activities aimed at occupying the residents' time. Participants in the experimental group received lifestyle redesign programme (i.e. the $3 \mathrm{LP}$ ) for six months conducted by occupational therapists. Each participant in the experimental group received 
2 hours of group sessions and one hour of an individual session per week. The model of the programme is shown in Figure 1. The programme was inspired by a successful lifestyles redesign programme; the Lifestyle Matters programme (Mountain et al., 2008).

Data was analysed using SPSS Version 12. The Mann-Whitney U test was conducted to determine compatibility between the experimental and control group pre-test scores on the demographic variables and the WHOQoL-Bref. Wilcoxon Signed Rank test was used to accept or reject the null hypothesis. An alpha level of 0.5 was used to determine whether there was any significant difference between the pre-test and post-test values. Acceptance or rejection of the hypothesis were based on a 95\% confidence interval $(\mathrm{Cl})(\mathrm{p}<0.05)$. In addition, standard mean differences were identified based on Cohen's effect size (Cohen, 1988).

\subsection{Results and Discussions}

The total numbers of residents who participated in the study were 82 (Figure 2).

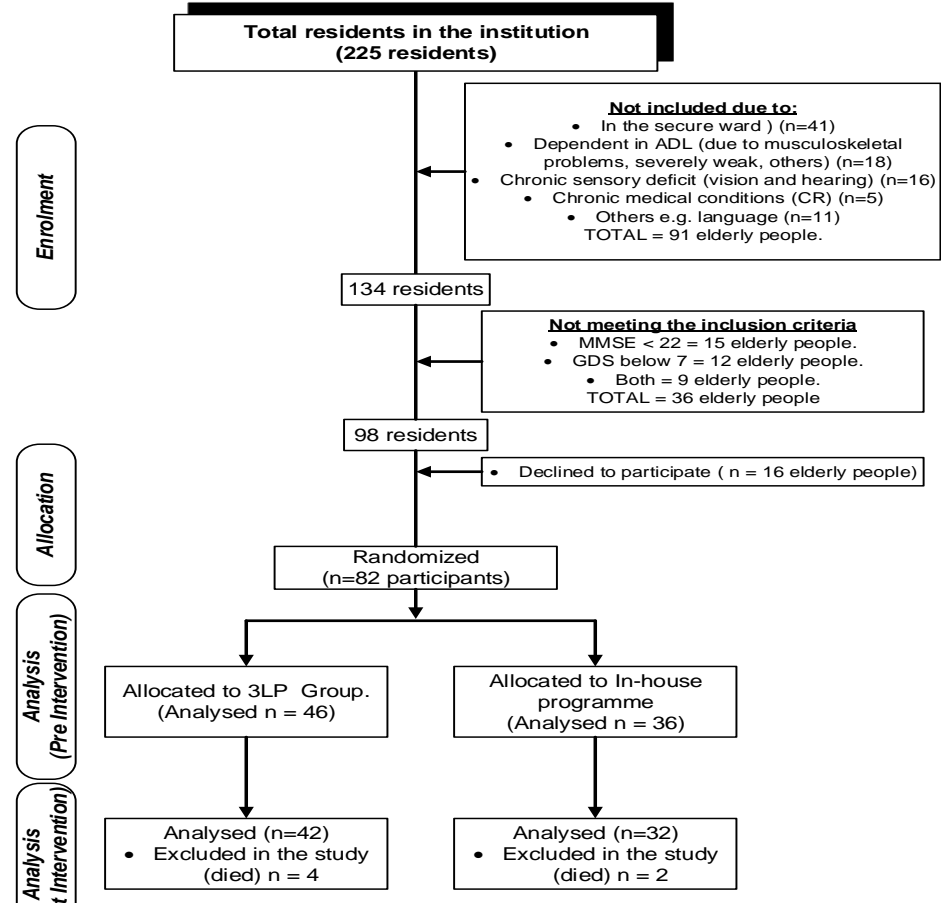

Figure 2: 3LP Programme model. 
Dahlan, A., \& Sultan Ibrahim, S.A. / Asian Journal of Quality of Life, AjQoL, 2(6), Apr / Jun 2017 (p.1-10)

Table 1: Socio-demographic characteristic of the participants

\begin{tabular}{|c|c|c|c|c|c|}
\hline Variables / Group & $\begin{array}{l}\text { Experiment } \\
\mathrm{N}(\%)\end{array}$ & $\begin{array}{l}\text { Control } \\
\mathrm{N}(\%)\end{array}$ & (u) & Z scores & $\mathrm{p}$-value \\
\hline \multicolumn{6}{|l|}{ Gender } \\
\hline Male & $28(60.9)$ & $28(77.8)$ & \multirow{3}{*}{688.0} & \multirow{3}{*}{-1.62} & \multirow{3}{*}{0.11} \\
\hline Female & $18(39.1)$ & $8(22.2)$ & & & \\
\hline Total & $46(100)$ & $36(100)$ & & & \\
\hline \multicolumn{6}{|l|}{ Age } \\
\hline 60 to 75 years old & $25(54.3)$ & $20(55.6)$ & \multirow{3}{*}{782.0} & \multirow{3}{*}{-0.43} & \multirow{3}{*}{0.66} \\
\hline above 75 years old & $21(45.7)$ & $16(44.4)$ & & & \\
\hline Median age (IQR) : & $\begin{array}{c}74.0 \\
(68.25-80.0)\end{array}$ & $\begin{array}{c}74.50 \\
(67.25-80.0)\end{array}$ & & & \\
\hline \multicolumn{6}{|l|}{ Race } \\
\hline Malay & $33(71.7)$ & $23(63.9)$ & \multirow{4}{*}{774.0} & \multirow{4}{*}{-0.62} & \multirow{4}{*}{0.54} \\
\hline Chinese & $9(19.6)$ & $11(30.6)$ & & & \\
\hline Indian & $4(8.7)$ & $1(2.8)$ & & & \\
\hline Others & - & $1(2.8)$ & & & \\
\hline \multicolumn{6}{|l|}{ Duration in institution } \\
\hline 1 to 36 months & $41(89.1)$ & $29(80.6)$ & \multirow{6}{*}{774.0} & \multirow{6}{*}{-0.51} & \multirow{6}{*}{0.61} \\
\hline 37 to 72 months & $4(8.7)$ & $5(13.9)$ & & & \\
\hline 73 to 180 months & $1(2.2)$ & & & & \\
\hline 181 to 144 months & 0 & $1(2.8)$ & & & \\
\hline (4) & 0 & $1(2.8)$ & & & \\
\hline Duration median (IQR) & $\begin{array}{l}26.0(13.50- \\
\quad 45.25)\end{array}$ & $\begin{array}{c}32.0(12.25- \\
58.75)\end{array}$ & & & \\
\hline \multicolumn{6}{|l|}{ WHOQoL - Bref } \\
\hline \multicolumn{6}{|l|}{ Domain 1: } \\
\hline $\begin{array}{l}\text { Physical Health } \\
\text { Median (IQR) }\end{array}$ & $\begin{array}{c}13.10 \\
(12.0-14.4)\end{array}$ & $\begin{array}{c}13.40 \\
(12.0-14.3)\end{array}$ & 755.0 & -0.61 & 0.54 \\
\hline \multicolumn{6}{|l|}{ Domain 2 : } \\
\hline $\begin{array}{l}\text { Psychological } \\
\text { Median (IQR) }\end{array}$ & $\begin{array}{c}13.80 \\
(11.3-14.0)\end{array}$ & $\begin{array}{c}13.40 \\
(11.3-13.2)\end{array}$ & 763.5 & -0.61 & 0.54 \\
\hline Domain 3: & 12.00 & & & & \\
\hline $\begin{array}{l}\text { Social relationship } \\
\text { Median (IQR) }\end{array}$ & $(11.7-16.0)$ & $\begin{array}{c}12.00 \\
(11.0-14.7)\end{array}$ & 790.5 & -0.36 & 0.72 \\
\hline $\begin{array}{l}\text { Domain 4: Environment } \\
\text { Median (IQR) }\end{array}$ & $\begin{array}{c}12.80 \\
(11.0-14.0)\end{array}$ & $\begin{array}{c}12.00 \\
(11.1-14.0)\end{array}$ & 797.0 & -0.29 & 0.77 \\
\hline $\begin{array}{l}\text { Total scores WHOQOL- } \\
\text { Bref } \\
\text { Median (IQR) }\end{array}$ & $\begin{array}{c}51.44 \\
(48.1-55.9)\end{array}$ & $\begin{array}{c}51.50 \\
(45.7-54.5)\end{array}$ & 731.0 & -0.91 & 0.37 \\
\hline
\end{tabular}

Abbreviations: $\mathrm{N}$ = number of participants, IQR = Inter quartile range, WHOQOL-Bref = Brief version of World Health Organisation Quality of Life, 
There is no statistically significant difference between experimental group and control group $(p>0.05)$ on demographic variables and pre-test scores of the WHOQoL-Bref (Table 1). After six months of the intervention, 76 participants completed the 3LP programmes. The post-test results indicated that there are statistically significant differences for participants in the experimental group in all domains of the WHOQoL-Bref as shown in Table 2. The scores are comparable with the norms of an international elderly people (Skevington et al. 2004; Hawthorne, et al, 2006) and elderly people in the community in Taiwan and Turkey (Hwang et al. 2003) but slightly lower than elderly people in Australia (Ikin et al. 2009).

Table 2: Socio-demographic characteristic of the participants

\begin{tabular}{|c|c|c|c|c|c|}
\hline \multirow{2}{*}{$\begin{array}{c}\text { WHOQoL - Bref } \\
\text { Domain }\end{array}$} & Baseline & After six months & \multirow{2}{*}{ Z score } & \multirow{2}{*}{$p$ value } & \multirow[b]{2}{*}{ d } \\
\hline & Median (IQR) & Median (IQR) & & & \\
\hline \multicolumn{6}{|c|}{ Domain 1: Physical health } \\
\hline Exp. Group & $\begin{array}{c}13.34 \\
(12.00-14.23)\end{array}$ & $\begin{array}{c}14.87 \\
(14.29-16.14)\end{array}$ & -5.08 & 0.02 & 0.58 \\
\hline $\begin{array}{l}\text { Control } \\
\text { Group }\end{array}$ & $\begin{array}{c}12.57 \\
(12.00-14.29)\end{array}$ & $\begin{array}{c}12.57 \\
(12.00-13.86)\end{array}$ & -0.04 & 0.97 & 0.00 \\
\hline \multicolumn{6}{|c|}{ Domain 2: Psychological health } \\
\hline Exp. Group & $\begin{array}{c}12.66 \\
(11.33-14.00)\end{array}$ & $\begin{array}{c}14.00 \\
(13.33-15.33)\end{array}$ & -4.04 & 0.03 & 0.46 \\
\hline $\begin{array}{l}\text { Control } \\
\text { Group }\end{array}$ & $\begin{array}{c}12.00 \\
(11.33-13.17)\end{array}$ & $\begin{array}{c}12.00 \\
(10.67-12.67)\end{array}$ & -1.23 & 0.22 & 0.14 \\
\hline \multicolumn{6}{|c|}{ Domain 3: Social relationship } \\
\hline Exp. Group & $\begin{array}{c}12.00 \\
(11.67-16.00)\end{array}$ & $\begin{array}{c}16.00 \\
(14.00-16.33)\end{array}$ & -3.71 & 0.02 & 0.43 \\
\hline $\begin{array}{l}\text { Control } \\
\text { Group }\end{array}$ & $\begin{array}{c}12.00 \\
(11.00-14.67) \\
\end{array}$ & $\begin{array}{c}12.00 \\
(10.50-14.17) \\
\end{array}$ & -1.12 & 0.26 & 0.13 \\
\hline \multicolumn{6}{|c|}{ Domain 4: Environment } \\
\hline Exp. Group & $\begin{array}{c}12.75 \\
(11.00-14.00) \\
\end{array}$ & $\begin{array}{c}13.24 \\
(121.50-14.50)\end{array}$ & -2.47 & 0.05 & 0.28 \\
\hline $\begin{array}{l}\text { Control } \\
\text { Group }\end{array}$ & $\begin{array}{c}12.00 \\
(11.13-14.00) \\
\end{array}$ & $\begin{array}{c}12.00 \\
(11.50-13.50) \\
\end{array}$ & -1.09 & 0.28 & 0.13 \\
\hline \multicolumn{6}{|l|}{ Total scores } \\
\hline Exp. Group & $\begin{array}{c}51.44 \\
(48.07-55.91) \\
\end{array}$ & $\begin{array}{c}58.45 \\
(55.57-60.76)\end{array}$ & -4.98 & 0.02 & 0.57 \\
\hline $\begin{array}{l}\text { Control } \\
\text { Group }\end{array}$ & $\begin{array}{c}51.50 \\
(45.75-54.51)\end{array}$ & $\begin{array}{c}49.73 \\
(45.29-53.69) \\
\end{array}$ & -1.13 & 0.26 & 0.26 \\
\hline
\end{tabular}

$I Q R=$ interquartile range,$d=$ effect size, WHOQoL-Bref = Brief version of World Health Organisation Quality of Life, $\operatorname{Exp}=$ Experimental gr

An increased in the physical domain in WHOQoL is postulated to have been contributed from engagement in activities that requires physical movement. These activities contributed to increasing in musculoskeletal functions, such as strength, endurance, balance and 
coordination. Previous RCT's and longitudinal studies indicates that engagement in physical related activities such as gardening and walking improved physical related functions such as muscular strength, balance and range of movement (Resnick et al. 2009; Egan and Mantes, 2010; Frandin, et, al, 2013), increased physical function and fitness (Shin et al. 2009; Lee, Lee and Woo, 2010, Frandin, et, al, 2013).

The second largest effect of the 3LP is towards the psychological domain in WHOQOLBref (medium effect, $r=0.46$, the median increment from 12.66 to 14.00). The experience of enjoyment in life was obtained through engagement with varieties of meaningful activities as planned in 3LP. Previous studies show that engagement in activities facilitates positive affect, such as feelings of happiness (Elavsky et al. 2005; Meeks, et al., 2007), fun and contentment with life (Harmer and Orrell, 2008) and reduction in depression (Resnick et al. 2008; Shin et al. 2009; Cheng, et al., 2012) and improved quality of life (Guallar-Castillón, 2014) and as stressed in many occupational therapy literatures (Egan and Mantes, 2010; Lee et al., 2010, Frandin, et, al. 2013).

It is speculated that the benefits of changes in physiological, psycho-social and psychological functions are interrelated; in which one benefit could facilitate enhancement in other benefits. For example, changes in musculoskeletal function (i.e.; increased walking endurance) could provide enhancement in psychological function (i.e.; feeling happy, increased self-esteem and had future direction in life) and the changes in musculoskeletal function could also encourage participants to engage in activities outside the institute.

Statistical significant changes in QoL scores could also be mediated by the unique characteristics of the core content of the $3 \mathrm{LP}$. The $3 \mathrm{LP}$ provides opportunities for the participants to engage in activities that are individualised and meaningful to them, minimised barriers and providing motivations. Individualised activities motivates participation and facilitate quality of life (Vriendt, et.al., 2014) and more responsiveness to institutionalised older people (Cohen-Mansfield, et al., 2010; Kolanowski \& Buettner, 2008), increased adherence (Findoff, Wyman \& Gross, 2009), reduced anxiety in relation to participation (Sung, Chang \& Lee, 2010), enables the development of feelings of proficiency and success (Holthe, et al., 2007). Eliminating barriers to engagement and provide motivation facilitates enhancement in self-efficacy and confidence through a reduction in stress which eventually facilitate success in engagement in activities (Shin et al., 2009). Furthermore, based on a systematic review, it is found that individualised intervention is more effective than 'blanket' programmes or control programme (Suhonen, et al., 2008).

Another characteristic of individualised activity in 3LP is that the activity conducted are interesting and challenging, yet not exceeding participants physical capacity, related to previous roles in life, self-identity and belong to a regular pattern of life as prior life before relocation to the institution. For example, gardening, craft, cooking, indoor and outdoor activities. Engagement in activities related to life roles facilitate a sense of well-being and provide a sense of connection between past and present (Harmer \& Orrell, 2008; Frandin, et.al, 2013). 
One of the limitations of the study is its limited sample size. Further studies that enrol a greater number of participants are, therefore, warranted to provide stronger and conclusive evidence regarding the effectiveness of the 3LP in facilitating enhancement in QoL.

\subsection{Conclusion}

Our results indicated that $3 \mathrm{LP}$, a lifestyle redesign programme which is similar to lifestyle redesign programme that was conducted for community-dwelling older people in Western countries facilitate improvement in QoL amongst older people in the institution. Therefore, we suggest that lifestyle redesign programme which focuses on active engagement or reengagement in meaningful, individualised, self-directed and valued activities should be a part of the rehabilitation programme for older people in institutions.

\section{Acknowledgement}

The authors wish to thank Faculty of Health Sciences, University Teknologi MARA (UiTM) and Research Management Institute (RMI), UiTM and the Department of Social Welfare for permission to conduct the study and to all participants in the study. This research was funded by Fundamental Research Grant (FRGS), Fasa 1/2012 (600-RMI/FRGS 5/3 (70/2012).

\section{References}

Boyce, R.D., Hanlon, J.T., Karp, J.F., Kloke, J., Saleh, A., Handler, S.M. (2012). A Review of the Effectiveness of A Depressed Nursing Home Residents Journal of the American Medical Directors Association, 13(4), 326-331.

Buchner, A; Erdfelder, E and Paul, F (1996). GPower : A general power analysis programme. Behaviour Resear Computers. 28(1): 1-11.

Cheng, S.T., Lee, C.K., Chow, P.K. (2010). Social support and psychological well-being of nursing home residents Psychogeriatrics, 10, 1-6.

Cheng, S.T., Chow, P.K., Yu, E.C.S., Chan, A.C.M. (2012). Leisure Activities Alleviate Depressive Symptoms in A Very Mild or Mild Dementia. The American Journal of Geriatric Psychiatry, 20(10), 904-908.

Choi, N. G., Ransom, S., \& Wyllie, R. J. (2008). Depression in older nursing home residents: the influence of stressors, coping, and acceptance of group and individual therapy. Aging \& Mental Health 12, 536-547.

Chuang, Y.H. and Abbey, J. (2009). The culture of a Taiwanese nursing home. Journal of Clinical Nursing. 18. 164(

Chung, J.C.C. (2004). Activity participation and well-being of older people with dementia in long term-care s Participation and Health. 24 (1), 22-31.

Cohen, J. (1988). Statistical power analysis for the behavioral sciences (2nd ed.). Hillsdale, NJ: Erlbaum. 
Cohen-Mansfield, J., Marx, M.S., Thein, K., Dakheel-Al, M. (2010). The impact of past and present preferences nursing home residents with dementia. Aging and Mental Health, 14(1), 67-73.

Cook, G., and Stanley, D. (2009). Quality of life in care homes: Message from the voices of older people. Journal c 3(4), 391-407.

Custers, A.F.J., Westerhof, G.J., Kuin, Y., Gerritsen, D.L., Riksen-Walraven, J.M. (2012). Relatedness, autonc caring relationship: The perspective of nursing home residents. Journal of Aging Studies, 26(3), 319-326.

Dahlan, A.; Ibrahim, S.A.S. (2014). Engagement in activity of interest and Quality of life amongst institutionalise Indian Journal of Health and Wellbeing. 5(2), 165-171.

Egan, B.A., Mentes, J.C. (2010). Benefits of physical activity for knee osteoarthritis. Journal of Gerontological Nursin

Elavsky, S., McAuley, E., Motl, R.W., Konopack, J.F., and David X. Marquez, D.X., Hu, L., Jerome, G.J., Diener enhances long-term quality of life in older adults: Efficacy, esteem, and affective influences. Annals of Behavioural $\mathrm{M}$

Findorff, M.J., Wyman, J.F., Gross, C.R. (2009). Predictors of long-term exercise adherence in a community-ba Journal of Women's Health, 18 (11), 1769-76.

Frandin, K., Grönstedt, H., Bergland, A., Helbostad, J.L., Puggaard, L., Andresen, M., Granbo, R., Hellstri daily activities for residents in Nordic nursing home settings - A randomized, controlled trial - Results: After 3 mon Geriatric Medicine, 4(1), S105-S106.

Fukahori, H., Matsui, N., Mizuno, Y., Yamamoto-Mitani, N., Sugai, Y., Sugishita, C. (2007). Factors relat home residents in Japan. Archives of Gerontology and Geriatrics, 45 (1), 73-86.

Guallar-Castillón, P., Bayán-Bravo, A., León-Muñoz, L.M., Balboa-Castillo, T., López-García, E., Gutierrez-Fisac (2014). The association of major patterns of physical activity, sedentary behavior and sleep with health-related , Preventive Medicine, 67, 248-254.

Harmer, B.J., and Orrell, M. (2008). What is meaningful activity for people with dementia living in care homes? A cor people with dementia, staff and family carers. Aging and Mental Health, 12(5), 548-558

Hasanah, C.I., Naing, L and Rahman, A.R.A. (2003). World Health Organisation Quality og Life Assessment: Brief Medical Journal of Malaysia. 58(1), $79-88$.

Haslam, L. (2008). Occupational participation at 85 plus: A review of the literature. New Zealand Journal of Occupa

Hawthorne, G., Herrman, H., Murphy, B. (2006). Interpreting the WHOQOL-Breff: Preliminary population norms and Research, 77(1), 37-59.

Hedberg, P., Brulin, C., Alex, L., and Gustafson, Y. (2010). Purpose in life over a five-year period: a longitudinal s International Psychogeriatrics, 16, 1-8.

Holthe, T., Thorsen, K., Josephsson. S. (2007). Occupational patterns of people with dementia in residential ( Scandinavian Journal of Occupational Therapy. 14 (2), 96-107.

Hwang, H.F., Liang, W.M., Chiu, Y.N., and Lin, M.R. (2003). Suitability of the WHOQOL-BREF for community-dwr Age and Ageing, 32(6), 593-600. 
Ice, G.H. (2002). Daily life in a nursing home. Has it changed in 25 years?. Journal of Aging Studies, 16, 345-359. Ikin, J.F., Sim, M.R., McKenzie, D.P., Horsley, K.W.A., Wilson, E.J., Harrex, W.K., Moore, M.R., Jelfs, P.L., Hendersı and quality in Korean War veterans five decades after the war. Journal of Epidemiology and Community Health, 63 ( $\Sigma$

Kolanowski, A., and Litaker, M. (2006). Social interaction, premobid personality, and agitation in nursing home resic of Psychiatric Nursing, 20(1), 15-22.

Lee, G.E. (2010). Predictors of adjustment to nursing home life of elderly residents: a cross-sectional survey. Int Studies, 47 (8), 957-64.

Lee, L.Y.K., Lee, D.T.F., Woo, J. (2010). The psychosocial effect of Tai Chi on nursing home residents. Journal of ( 938.

Mountain, G; Mozely, C; Craig, C and Ball, L (2008) Occupational therapy led health promotion for older people: Feasibility of the Lifestyle Matters Programme. British Journal of Occupational Therapy. 71(10), $406-413$.

Neikrug, A.B., and Ancoli-Israel, S. (2010). Sleep disturbances in nursing homes. The Journal of Nutrition Health and Aging. 14(3), 207-2011.

Resnick, B., Gruber-Baldini, A.L., Zimmerman, S., Galik, E., Pretzer-Aboff, I., Russ, K., Hebel, J.R. (2009). Nursing home resident outcomes from the Res-Care intervention. Journal of the American Geriatrics Society, 57 (7), 1156-1165.

Saghaei, M. (2004). Random Allocation Software. [Online] Available from < http://mahmoodsaghaei.tripod.com/Softwares/randalloc.html> [Access November 3 2013].

Skevington, S., Lofty, M., O'Connell, K.A. (2004). The World Health Organisation's WHOQOL-BREF quality of life assessment: Psychometric properties and results of the international field trial. Quality of Life Research, 13(2), 299-310.

Spilsbury, K., Hewitt, C., Stirk, L.,Bowman, C.(2011).The relationship between nurse staffing and quality of care in nursing homes: A systematic review. International Journal of Nursing Studies, 48(6), 732-75.

Suhonen, R., Valimaki, M., Leino-Kilpi, H. (2008). A review of outcomes of individualised nursing interventions on adult patients. Journal of Clinical Nursing, 17 (7), 843-860.

Sung, H., Chang, A.M., Lee, W. (2010). A preferred music listening intervention to reduce anxiety in older adults with dementia in nursing homes. Journal of Clinical Nursing, 19 (7-8), 1056-1064.

Vriendt, P.D., E. Cornelis, E, Desmet,V., Vanbosseghem, R., Van Malderen, L., Gorus, E., D. de Velde, V (2014). P527: Quality of life and meaningful activities in residential care: the Active Ageing (AA) concept challenged. European Geriatric Medicine, 5(1), S249-S250.

World Health Organization Quality of Life Group. (1995). The World Health Organization Quality of Life assessment: Position paper from the World Health Organization. Social Science and Medicine, 41(10), 14031409 . 